Number of words: 7764

Number of pages: 26

Number of illustrations: 2

Number of tables: 5

\title{
VIBROTACTILE THRESHOLDS AT THE FINGERTIP, VOLAR FOREARM, LARGE TOE, AND HEEL
}

\section{Authors:}

Miyuki Morioka, Darren J. Whitehouse and Michael J. Griffin

Human Factors Research Unit

Institute of Sound and Vibration Research

University of Southampton

Southampton, SO17 1BJ

England

Tel: $+44(0) 2380592277$

Fax:+44 (0)23 80592927

e-mail: M.J.Griffin@soton.ac.uk

Running title:

Effect of contact location on vibrotactile thresholds

Key words:

Vibration, threshold, tactile channel, contact location 


\begin{abstract}
Thresholds for the perception of vibration vary with location on the body due to the organisation of tactile channels in hairy and non-hairy skin, and variations in receptor density. This study determined vibration thresholds at four locations on the body with two different contactors so as to assist the identification of the tactile channel determining the threshold at each location. Vibrotactile thresholds at six frequencies from 8 to $250 \mathrm{~Hz}$ were measured on the distal phalanx of the index finger, the volar forearm, the large toe, and the heel with two contactors: (i) a 1-mm diameter circular probe with a 1-mm gap to a fixed circular surround (i.e. 7.1- $\mathrm{mm}^{2}$ excitation area), and (ii) a 6-mm diameter circular probe with a 2-mm gap to a fixed circular surround (i.e. $79-\mathrm{mm}^{2}$ excitation area). At all frequencies and with both contactors, thresholds on the fingertip were lower than thresholds on the volar forearm, the large toe, and the heel, consistent with a greater density of mechanoreceptors at the fingertip. Thresholds with the larger contactor were lower than thresholds with the smaller contactor on the fingertip at high frequencies $(63,125$ and $250 \mathrm{~Hz})$, on the large toe (except at $250 \mathrm{~Hz}$ ), on the heel (at all frequencies), and on the volar forearm at $250 \mathrm{~Hz}$. It is concluded that at least two tactile channels (Pacinian from 63 to $250 \mathrm{~Hz}$, and non-Pacinian from 8 to $31.5 \mathrm{~Hz}$ ) determined vibrotactile thresholds at the fingertip, whereas non-Pacinian channels had a dominant influence on vibrotactile thresholds at the volar forearm. The role of Pacinian and non-Pacinian channels could not be confirmed at the large toe or the heel despite some evidence of spatial summation.
\end{abstract}




\section{Introduction}

Vibrotactile thresholds on the glabrous skin of the hand are reported to be determined by one of four psychophysical channels (Bolanowski et al. 1988). The Pacinian (P) channel, mediated by the Pacinian corpuscles, has the lowest threshold at frequencies between approximately 40 and $400 \mathrm{~Hz}$ when using a 6.4-mm contactor (Verrillo, 1962, 1963), and exhibits both spatial and temporal summation: reduced thresholds with increased area of excitation and increased duration of vibration. Of the three non-Pacinian channels, NPI often determines thresholds at frequencies between 2 and $40 \mathrm{~Hz}$ and has the Meissner corpuscle as the mechanoreceptor associated with rapidly adapting (RA) fibers (Bolanowski et al. 1988). Two further non-Pacinian channels, NPII (Capraro et al. 1979) and NPIII (Bolanowski et al. 1988), are associated with slowly adapting (SA) fibers and have been identified from the results of psychophysical experiments. The NPII channel responds to vibration in the same frequency range as the Pacinian channel but is directionally sensitive to the stretching of the skin and has a higher threshold than the Pacinian channel (Bolanowski et al. 1988). The mechanoreceptor for the NPII channel has not yet been identified neurophysiologically in humans, but may be similar in structure to Ruffini endings (Verrillo et al. 2002). The NPIII channel may have a lower threshold than other channels in the range 0.4 and $4 \mathrm{~Hz}$ and has Merkel discs as the mechanoreceptor. For these four channels, similar frequency responses have been found in psychophysical studies and in neurophysiological responses of individual nerve fibres (Greenspan and Bolanowski, 1996).

The contact conditions between the skin and a source of vibration affect which of the four channels has the lowest threshold. So, in addition to the frequency of vibration, the surface area of the contactor (Verrillo, 1962), the probe shape (Verrillo, 1963), the gap between the probe and the surround (Harada and Griffin, 1991), and the upward contact force of the probe (Lindsell, 1997) combine to determine the threshold for the perception of vibration at any location on the body.

Variations in sensitivity to vibrotactile stimuli over the surface of the body (Gregg, 1951; Wilska, 1954) have been attributed partly to differences in the density of mechanoreceptors between different areas of skin over the body and partly to a difference in the anatomical and physiological organisation between glabrous skin and hairy skin (Burgess, 1973; Järvilehto et al., 1981).

The density of mechanoreceptors varies over the glabrous skin of the hand. The distal half of the fingertip has a greater density of Meissner corpuscles (FAI), Merkel discs (SAI) and Pacinian corpuscles (FAll) than the proximal half of the finger and the palm of the hand. At 
the fingertip, the density of the edge-sensitive receptors (SAI and FAI) is greater than the density of Pacinian corpuscles (FAII). There are reported to be approximately $140 \mathrm{FAI}$ units and $70 \mathrm{SAI}$ units per $\mathrm{cm}^{2}$ in the distal half of the terminal phalanx compared to 20 FAll units and 49 SAll units per $\mathrm{cm}^{2}$ (Johansson and Vallbo, 1979). Although the density of mechanoreceptors on the hand increases from the palm toward the fingertip, the distribution of receptors is similar at the toes and the heel (Kennedy and Inglis, 2002). The receptive fields (the areas of skin that when stimulated evoke a response in the afferent nerve fibre) of the SAll units (Ruffini) and FAll units (Pacinian) are similar on the hand and the foot, but the receptive fields of the FAI units (Meissner) and SAI units (Merkel Discs) on the foot are approximately twice the area of those on the hand (Trulsson, 2001). This is consistent with the foot not needing the high level of spatial acuity required at the fingertip when exploring objects.

In the hairy skin of the human forearm, five main types of mechanoreceptors with large myelinated afferents were identified by Vallbo et al. (1995): SA I, SA II, hair units, field units, and Pacinian-type units. The latter three unit types were all rapidly adapting (RA). Meissner corpuscles (FA I) were absent from the hairy skin. Detection of vibrotactile stimuli in hairy skin is thought to involve at least three types of tactile receptors, the Pacinian corpuscles, the slowly adapting type II (SA II) fibers and the rapidly adapting (RA) fibers (Bolanowski et al., 1994). The RA fibers in the hairy skin are mediated by the hair follicle afferent (HFA) fibers and are considered responsible for detecting vibration at frequencies up to $80 \mathrm{~Hz}$ (Zachariah et al., 2001; Mahns et al., 2006). In the forearm, Pacinian corpuscles are typically located in deeper tissues, especially surrounding joints and bone, but can be excited by high frequency vibration (greater than $80 \mathrm{~Hz}$ ) applied to the skin surface (Mahns et al., 2006). The densities of RA units are lower in hairy skin than in glabrous skin (Edin and Abbs, 1991; Järvilehto et al. 1981), and may explain some of the differences in vibrotactile sensitivity between glabrous and hairy skin. Verrillo (1966) found sensitivity to $250 \mathrm{~Hz}$ vibration approximately $20 \mathrm{~dB}$ less at the volar forearm than at the thenar eminence when using a 4$\mathrm{mm}$ diameter probe with a 1-mm gap to a surround. Thresholds on the forearm have been reported to be determined by non-Pacinian receptors at frequencies from 12 to $500 \mathrm{~Hz}$ (Verrillo and Bolanowski, 1986).

Several psychophysical studies have measured vibrotactile thresholds on the foot (e.g. Nurse and Nigg, 1999; Kowalzik et al. 1996; Bartlett et al. 1998) but none of these identified the channels mediating the thresholds. The contact conditions between the skin and the source of vibration have not always been specified in sufficient detail to replicate the reported measurements. Kekoni et al. (1989) determined perception thresholds for vibration at 20,80 and $240 \mathrm{~Hz}$ at eight locations on the foot with 2-mm and 8-mm diameter probes. 
Thresholds obtained with the larger contactor were significantly lower than those obtained with the smaller contactor at 80 and $240 \mathrm{~Hz}$, suggesting thresholds at 80 and $240 \mathrm{~Hz}$ were probably determined by the Pacinian channel. The regional differences in sensitivity between locations on the foot were greater at 80 and $240 \mathrm{~Hz}$ than at $20 \mathrm{~Hz}$, which was partly explained by different spreading at the two frequencies of high-frequency vibration due to different mechanical properties over the skin areas. They did not employ a surround that would be expected to enhance the perceptibility of low frequency vibration (by increasing the gradient of stimuli) and limit the spread of high-frequency vibration across the skin.

There are no known studies systematically comparing the vibrotactile sensitivity of the foot and the fingertip with well specified stimuli. If the same mechanoreceptor nerve endings are responsible for perception in the glabrous skin of the fingertip and the sole of the foot, thresholds at each location would be expected to react in a similar way to changes in the contact conditions between a vibrating probe and the skin.

This study was designed to compare sensitivity to vibration stimuli between four body locations: the glabrous skin of the hand (i.e. fingertip), the glabrous skin of the foot (i.e. large toe and heel), and hairy skin (i.e. volar forearm), while controlling contact conditions between the skin and the vibrating probe. The vibrotactile thresholds were expected to show differences that could be explained by the contact conditions and the underlying activity of Pacinian and non-Pacinian channels. It was hoped that the results would contribute to understanding of the receptors responsible for vibration perception at each location.

On the glabrous skin of the fingertip, the large toe and the heel, it was expected that the Pacinian channel would have the lowest threshold at high frequencies (i.e. 63, 125 and 250 $\mathrm{Hz}$ ) and would therefore determine the vibrotactile threshold. Consequently, it was hypothesised that, at these three locations, the high frequency thresholds would decrease with an increase in the area of excitation due to spatial summation within the Pacinian channel. The lower density of Pacinian corpuscles on the hairy skin of the volar forearm, suggested that any spatial summation would be weaker at this location.

Non-Pacinian channels were expected to have the lowest thresholds at low frequencies (i.e. 8, 16, and $31.5 \mathrm{~Hz}$ ). It was hypothesised that thresholds at these lower frequencies would not decrease with increased area of excitation because non-Pacinian channels do not exhibit spatial summation.

It was expected that at all frequencies, and with both contactors, thresholds at the fingertip would be lower than thresholds on the volar forearm, the large toe and the heel, due to the presumed higher density of all four types of mechanoreceptors at the fingertip. 


\section{Materials and Methods}

\subsection{Subjects}

Sixteen male subjects with median (range) age $26.5(21$ - 38) years, stature 178 (163.5 $186.0) \mathrm{cm}$, and weight 73.1 (63.4 - 100.9) kg participated in the experiment. The experiment was approved by the Human Experimentation, Safety and Ethics Committee of the Institute of Sound and Vibration Research at the University of Southampton. The subjects were without known causes of peripheral neuropathy, such as diabetes or significant exposure to hand-transmitted vibration.

\subsection{Experimental conditions}

Vibrotactile thresholds were measured at six frequencies $(8,16,31.5,63,125$ and $250 \mathrm{~Hz})$ using an HVLab Vibrotactile Perception Meter at four locations: (i) the centre of the whorl on the distal phalanx of the right index finger, (ii) $100 \mathrm{~mm}$ proximal to the crease of the wrist on the right volar forearm, (iii) the centre of the whorl of the large toe of the right foot, (iv) the centre of the heel of the right foot.

Two contactors were used: (i) a 1-mm diameter circular contactor $\left(0.78 \mathrm{~mm}^{2}\right.$ area) with a 1$\mathrm{mm}$ gap to a fixed circular surround (i.e. $7.1-\mathrm{mm}^{2}$ area of excitation), and (ii) a 6-mm diameter circular contactor $\left(28.0 \mathrm{~mm}^{2}\right.$ area) with a $2-\mathrm{mm}$ gap to a fixed circular surround (i.e. $79-\mathrm{mm}^{2}$ area of excitation) (Table 1).

\section{TABLE 1 ABOUT HERE}

The push force and skin indentation were also controlled. With both contactors, a $2 \mathrm{~N}$ push force was maintained on the static surround during the threshold measurements by the subjects (for the index finger) or by the experimenter (for the forearm, toe and heel) who monitored a force meter on the HVLab Vibrotactile Perception Meter. The contact surfaces of both contactors were flush with the surround.

The experiment was conducted in a quiet room with a temperature of $22^{\circ} \mathrm{C} \pm 2^{\circ} \mathrm{C}$. The subjects, who attended two sessions, were acclimatised to the room temperature for five minutes before commencing the experiment. Skin temperature was measured using a HVLab Thermal Aesthesiometer. Skin temperature was measured at the fingertip by the subject holding a thermocouple between the index finger and thumb. Temperature was measured at the volar forearm, the large toe and the heel by taping a thermocouple to each location using clinical Micropore tape. In session 1, the median (range) of skin temperatures were $33.9^{\circ} \mathrm{C}(21.7-35.4)$ at the fingertip, $32.8^{\circ} \mathrm{C}(30.5-33.6)$ at the volar forearm, $27.2^{\circ} \mathrm{C}$ $\left(23.9\right.$ - 32.6) at the large toe, and $28.1^{\circ} \mathrm{C}(25.0-32.2)$ at the heel. In session 2 , the 
temperatures were $34.0^{\circ} \mathrm{C}(25.0-35.4)$ at the fingertip, $32.9^{\circ} \mathrm{C}(30.7-33.6)$ at the volar forearm, $27.8^{\circ} \mathrm{C}(23.0-32.6)$ at the large toe, and $28.1^{\circ} \mathrm{C}(23.1-32.2)$ at the heel. Subjects wore ear defenders during the threshold measurements to assist concentration.

For threshold measurements at the fingertip, subjects rested the full length of their forearm on a support and applied the whorl of the index finger to the HVLab Vibrotactile Perception Meter surround with a push force of $2 \mathrm{~N}$. For thresholds on the volar forearm, subjects placed their forearm palm-up on a support and the HVLab Vibrotactile Perception Meter was applied by the experimenter with a push force of $2 \mathrm{~N}$. For thresholds on the large toe and on the heel, the lower right leg of the subject was supported parallel to the floor and the HVLab Vibrotactile Perception Meter was applied by the experimenter to the centre of the whorl of the large toe or the centre of the heel with a push force of $2 \mathrm{~N}$.

Thresholds were measured with continuous vibration using the von Békésy method (von Békésy, 1947) and HVLab software (v 4.23). The vibration increased in magnitude until the subject perceived the vibration and pressed a response button; the magnitude then decreased until the subject could no longer feel the vibration and released the response button. The magnitude of vibration increased by $5 \mathrm{~dB} / \mathrm{s}$, until the first response and then decreased and increased at $3 \mathrm{~dB} / \mathrm{s}$ for subsequent responses. A measurement was terminated 45 seconds after the first button press. Each button operation was defined as a 'reversal'. The reversals where the button was pressed were 'peaks' and the reversals where the button was released were 'troughs'. Thresholds were defined as the arithmetic mean of the vibration magnitude at the peaks and the troughs for all reversals excluding the first peak and first trough, and are reported in units of acceleration ( $\mathrm{ms}^{-2}$ r.m.s.).

\subsection{Experimental procedure}

Each subject participated in two 30-minute sessions on different days. Half of the subjects commenced with the $1-\mathrm{mm}$ contactor followed by the $6-\mathrm{mm}$ contactor and half commenced with the 6-mm contactor followed by the 1-mm contactor. Thresholds were measured at all four contact locations in each session: the contactor $(1 \mathrm{~mm}$ or $6 \mathrm{~mm}$ ) differed between sessions. The order of presentation of frequencies and test locations was balanced between subjects. Each subject gave practice thresholds at 31.5 and $125 \mathrm{~Hz}$ at the centre of the whorl of the middle finger before commencing the experiment.

\subsection{Statistical Methods}

Data were analysed using the Statistical Package for the Social Sciences (SPSS) version 10.0. Non-parametric statistical techniques, Friedman two-way analysis of variance and Wilcoxon matched-pairs signed ranks tests, were employed to investigate differences 
between repeated measures. Spearman's rank correlation was used to investigate relationships between variables.

\section{Results}

In both experimental sessions, there was a significant difference in skin temperature over the four contact locations (Friedman, $p<0.001$ ). The fingertip and the volar forearm were significantly warmer than the large toe and the heel in both sessions (Wilcoxon, $p<0.05$ ).

\subsection{Effect of contact location}

At all frequencies and with both contactors, there was a significant effect of contact location on thresholds (Friedman, $p<0.001$ ), with thresholds lower on the fingertip than on the forearm, the large toe and the heel (Wilcoxon, $p<0.05$, Figure 1, Table 2).

\section{FIGURE 1 AND TABLE 2 ABOUT HERE}

At all frequencies and with both contactors, thresholds were lower on the large toe and the heel than on the volar forearm $(p<0.05)$, except for no difference between thresholds on the large toe and the forearm at $250 \mathrm{~Hz}$ with both contactors.

With both contactors, thresholds on the large toe were lower than on the heel at 8, 16, 31.5 and $63 \mathrm{~Hz}$ (Wilcoxon, $p<0.05$ ), except at $8 \mathrm{~Hz}$ with the small contactor. With the large contactor, thresholds were lower on the heel than on the large toe at 125 and $250 \mathrm{~Hz}$ (Wilcoxon, $p<0.05)$.

3.2 Effect of contactor geometry - area of excitation and gap between contactor and surround

There was some evidence of spatial summation (i.e. lower thresholds with the larger area of excitation) at each location, as may be seen in Figure 2. At the fingertip and the volar forearm, thresholds were significantly lower with the larger contactor at high frequencies: greater than $63 \mathrm{~Hz}$ for the fingertip and greater than $125 \mathrm{~Hz}$ at the volar forearm (Wilcoxon, $p<0.05)$. At the large toe and the heel, thresholds were significantly lower with the larger contactor at all frequencies $(8,16,31.5,63,125$ and $250 \mathrm{~Hz}$ ) (Wilcoxon, $p<0.05)$, except at $250 \mathrm{~Hz}$ on the large toe.

At the fingertip, median thresholds at low frequencies $(8,16$, and $31.5 \mathrm{~Hz})$ were consistently lower with the smaller contactor than the larger contactor, although the difference was not statistically significant. The trend is consistent with a reduction in the gap (from $2 \mathrm{~mm}$ to 1 $\mathrm{mm}$ ) between the contactor and the surround increasing sensitivity to vibration at low frequencies. 


\section{FIGURE 2 ABOUT HERE}

\subsection{Correlations between thresholds at different frequencies}

The correlation between thresholds at two frequencies would be expected to be higher when the same channel mediates the thresholds than when different channels mediate the thresholds. Table 3 shows the correlations between thresholds at different frequencies measured with 1-mm and 6-mm contactors.

\section{$\underline{1-\mathrm{mm} \text { contactor }}$}

At all locations, thresholds obtained at $8,16,31.5$, and $63 \mathrm{~Hz}$ were correlated $(p<0.05)$, except at the fingertip between thresholds at 8 and $63 \mathrm{~Hz}$ and between 31.5 and $63 \mathrm{~Hz}$. At the forearm, thresholds at 8,16 , and $63 \mathrm{~Hz}$ were also correlated with $125-\mathrm{Hz}$ thresholds $(p<0.05)$ At all locations, thresholds at 125 and $250 \mathrm{~Hz}$ were correlated $(p<0.05)$.

\section{$\underline{6-\mathrm{mm} \text { contactor }}$}

At all locations, thresholds obtained at $8,16,31.5$ and $63 \mathrm{~Hz}$ were correlated $(p<0.05)$, except at all locations between thresholds at 16 and $63 \mathrm{~Hz}$ and on the forearm between thresholds at 31.5 and $63 \mathrm{~Hz}$. On the forearm, the large toe and the heel, thresholds at 8,16 , $31.5,63 \mathrm{~Hz}$ were also correlated with $125 \mathrm{-Hz}$ thresholds $(p<0.05)$ except at the large toe between thresholds at 8 and $125 \mathrm{~Hz}$. At all locations, thresholds at 63,125 and $250 \mathrm{~Hz}$ were correlated $(p<0.05)$.

\section{TABLE 3 ABOUT HERE}

\subsection{Correlations between thresholds obtained with small and large contactors}

The correlation between thresholds with different contactors would be expected to be higher when the same channel mediates thresholds than when different channels mediate thresholds.

At all frequencies and all locations, thresholds obtained with the small contactor were correlated with the thresholds obtained with the large contactor $(p<0.05)$, except for thresholds at $16 \mathrm{~Hz}$ on the fingertip and the large toe, and thresholds at $31.5,63$ and $250 \mathrm{~Hz}$ on the heel (see Table 4).

TABLE 4 ABOUT HERE 


\subsection{Correlations between thresholds at different locations}

The correlation between thresholds at two locations may be expected to be stronger when the same channel mediates thresholds than when different channels mediate the thresholds. As seen in Table 5, almost all correlations between thresholds at different locations were positive, indicating that subjects with a high threshold at one location were likely to have a high threshold at another location.

Although some correlations do not appear to be systematic, there are some clear trends. With the 1-mm contactor at 8 and $16 \mathrm{~Hz}$, the fingertip thresholds were significantly correlated with thresholds at the volar forearm, the large toe and the heel $(p<0.05)$, except at $8 \mathrm{~Hz}$ with the large toe. With the 6-mm contactor, thresholds on the large toe and thresholds at the heel were significantly correlated $(p<0.05)$, except at 63 and $250 \mathrm{~Hz}$.

\section{TABLE 5 ABOUT HERE}

\subsection{Correlations between thresholds and skin temperature}

There were no correlations between skin temperature and thresholds with either contactor at any location, except a positive correlation with $31.5 \mathrm{~Hz}$ and $125 \mathrm{~Hz}$ thresholds on the fingertip using the larger contactor, where thresholds increased with increasing temperature $(p<0.05)$.

\section{Discussion}

\subsection{Effect of contact location on thresholds}

It was hypothesised that thresholds on the fingertip would be lower than thresholds on the forearm, the large toe, and the heel because there is a greater density of mechanoreceptors at the fingertip. The results are consistent with this hypothesis with both contactors and at all frequencies (Figure 1). Similarly, the results are consistent with the hypothesis that high frequency thresholds would be lower with the larger contactor because it would excite a greater number of Pacinian corpuscles than the smaller contactor (Figure 2).

The Meissner corpuscles are assumed to determine thresholds at frequencies less than about $40 \mathrm{~Hz}$ on the fingertip (Bolanowski et al., 1988) and at $20 \mathrm{~Hz}$ at the sole of the foot (Kekoni et al., 1989). They are high in density at the fingertip (140 per $\mathrm{cm}^{2}$; Johansson and Vallbo, 1979) and, given the high levels of spatial acuity at the fingertip, may be presumed to be greater in density at the fingertip than at the large toe and the heel. In this study, low frequency vibrotactile thresholds were lowest on the fingertip; the higher thresholds at other locations may reflect a reduced density of Meissner corpuscles at these locations. 
The differences in sensitivity between locations may be consistent with the role each location plays in the perception of tactile stimuli. Fine spatial acuity at the fingertips assists the exploration of objects by the hand (Johansson and Vallbo, 1979), a task well suited to the edge-discriminating capability of Meissner corpuscles and, particularly, the Merkel discs innervating the glabrous skin of the human hand (Johansson et al., 1982). In contrast, the mechanoreceptors at the sole of the foot are responsible for the control of balance and weight-bearing actions and do not require high levels of spatial acuity (Kennedy and Inglis, 2002). The volar forearm also plays no obvious role in tactile discrimination.

The reduced sensitivity of vibrotactile thresholds at the forearm compared to other locations (the fingertip, the large toe and the heel) in the present results at all frequencies (see Figure 1) may be partly attributed to a different organisation of the tactile channels between the hairy skin and glabrous skin. With Pacinian corpuscles in hairy skin in deeper tissue and fewer in number than Pacinian corpuscles in glabrous skin (Burgess, 1973), it seems reasonable for high frequency thresholds to be higher at the forearm than on glabrous skin. Moreover, the absence of Meissner corpuscles in the hairy skin suggests that a different tactile channel, hair follicle afferent (HFA) fibers, were likely to have mediated thresholds at low frequencies with a consequent increase in low-frequency thresholds at the forearm, although the relative sensitivity of Meissner corpuscles and HFA fibres is unclear.

The distributions of FAI (Meissner) and FAll (Pacinian) units are reported to be similar at the large toe and the heel (Kennedy and Inglis, 2002) and so similar vibrotactile thresholds were expected for these locations at all frequencies and with both contactors. However, the measured thresholds were significantly lower on the large toe at low frequencies with both contactors, and significantly lower on the heel at high frequencies with the larger contactor (Figure 1), inconsistent with the density of receptors on the sole of the foot reported by Kennedy and Inglis (2002). The present thresholds are partly consistent with lower thresholds on the heel than the large toe at 80 and $240 \mathrm{~Hz}$ when using 2-mm and 8-mm diameter contactors (Kekoni et al., 1989).

Factors other than the distribution and density of mechanoreceptors may have affected thresholds. For example, the skin is thicker on the sole of the foot compared to the fingertip (Sequiera et al., 1947) and this be expected to increase thresholds at the foot. While Kekoni et al. (1989) speculated on possible influences of the mechanical properties of the skin on vibrotactile thresholds at the foot, it has been reported that the mechanical properties of the skin do not significantly affect discrimination thresholds (Kowalzik et al., 1996).

Skin temperature varied, with the fingertip warmer than the large toe and the heel, but this was probably not a dominating factor in the present results as only slight changes in 
threshold are expected with changes in skin temperature between 29 and $40^{\circ} \mathrm{C}$ (Bolanowski and Verrillo, 1982). Although some subjects had skin temperatures less than $29^{\circ} \mathrm{C}$, any effect was probably small as there were no correlations between skin temperature and thresholds (except for the fingertip at 31.5 and $125 \mathrm{~Hz}$ using the larger contactor). If skin temperature were the dominant factor responsible for the differences between contact locations, thresholds on the volar forearm would have been lower than thresholds on the large toe and the heel, since the forearm was significantly warmer than the large toe and the heel in both sessions.

\subsection{Effect of contactor geometry on vibrotactile thresholds}

The two contactors employed in the present study allowed the influence of spatial summation (evidence of the Pacinian channel) and gradient effects to be seen (evidence of the non-Pacinian channels, particularly associated with Meissner corpuscles and Merkel discs).

Low-frequency thresholds were expected to be lower with the smaller contactor that produced a sharper gradient on the skin, because of the smaller gap to the surround. This has been found with studies at the fingertip (Harada and Griffin, 1991) and can be seen in the low frequency thresholds of the present study at the fingertip where thresholds were consistently lower with the smaller gap (although not significantly lower) (Figure 2). This was not found on the volar forearm, the large toe or the heel, suggesting that the non-Pacinian channel at these locations was not sufficiently sensitive to changes in contactor geometry for the edge sensitive receptors to determine thresholds at these frequencies.

It was expected that high-frequency thresholds would be lower with the larger contactor (i.e. the larger excitation area) if thresholds were mediated by the Pacinian channel. According to the spatial summation theory proposed by Verrillo (1963), a 3-dB decrease is expected in the Pacinian threshold per doubling of contact area, so an increase in the area of stimulation from 7.1 to $79 \mathrm{~mm}^{2}$ (more than a factor of 10 ) would be expected to result in more than a 9$\mathrm{dB}$ decrease in threshold. The averages (over thresholds at 63, 125, and $250 \mathrm{~Hz}$ ) of the median spatial summation across subjects for the fingertip, the volar forearm, the large toe, and the heel were 10.2, 3.6, 3.2 and $6.5 \mathrm{~dB}$, respectively. So while the change in thresholds at the fingertip is consistent with spatial summation, those at the other locations are less than expected. This could occur if thresholds with the larger contactor were determined by the Pacinian channel but thresholds with the smaller contactor were determined by a nonPacinian channel. Alternatively, while the thresholds of some subjects may have been 
mediated by the Pacinian channel with both contactors, other subjects may have had one or both thresholds mediated by a non-Pacinian channel.

\section{Fingertip}

The thresholds at the fingertip are consistent with the hypothesis that high frequency thresholds would be mediated by the Pacinian channel while low frequency thresholds would be mediated by non-Pacinian channels. Thresholds at the high frequencies $(63,125$ and 250 $\mathrm{Hz}$ ) were significantly lower with the larger contactor, consistent with spatial summation in the Pacinian channel (Verrillo, 1963). Thresholds at the low frequencies (8, 16 and $31.5 \mathrm{~Hz})$ were not reduced with the larger contactor, consistent with these thresholds being mediated by non-Pacinian mechanoreceptors.

The correlations between thresholds at different frequencies are consistent different channels mediating thresholds at low and high frequencies. With the larger contactor, the correlations between thresholds at high frequencies $(63,125$ and $250 \mathrm{~Hz}$ ) were particularly strong, consistent with the Pacinian channel having increased influence with the larger area of excitation at these frequencies. There were also correlations between thresholds at low frequencies $(8,16$ and $31.5 \mathrm{~Hz}$ ) with both contactors (Table 3), suggesting that thresholds at these frequencies were determined by the same receptor. Thresholds at high frequencies $(63,125$ and $250 \mathrm{~Hz})$ were generally not significantly correlated with thresholds at the low frequencies (8, 16 and $31.5 \mathrm{~Hz}$ ) with either contactor (Table 3), implying that different channels mediated thresholds at low and high frequencies in most subjects. It seems probable that, within each frequency, the same channel mediated thresholds with both the small and the large contactor, since thresholds obtained with both contactors were correlated at all frequencies (Table 4) except at $16 \mathrm{~Hz}$. The pattern of correlations, both between frequencies, and between contactors, as well as the spatial summation only occurring at high frequencies, implies that thresholds at high frequencies $(63,125$ and 250 $\mathrm{Hz}$ ) were determined by the Pacinian channel with both contactors and that thresholds at lower frequencies $(8,16$ and 31.5$)$ were determined by non-Pacinian channels with both contactors, consistent with Whitehouse et al. (2006).

From the present results it is not possible to state definitively which non-Pacinian channel determined thresholds at low frequencies. Of the candidate non-Pacinian channels, the NPIII channel may not normally influence thresholds at frequencies greater than about $4 \mathrm{~Hz}$ (Bolanowski et al. 1988), suggesting this channel did not have the lowest thresholds at 8, 16 or $31.5 \mathrm{~Hz}$. At the thenar eminence, the NPII channel normally has a lower threshold than other channels only at frequencies greater than about $100 \mathrm{~Hz}$ when the contact area is small 
(Capraro et al. 1979). The NPI channel (Meissner's corpuscles) is therefore the channel most likely to have mediated the low frequency thresholds at the fingertip.

\section{Volar forearm}

Thresholds at the volar forearm were probably determined by non-Pacinian channels at most frequencies with both contactors. Absence of spatial summation at any frequency except $250 \mathrm{~Hz}$ suggests that thresholds at $125 \mathrm{~Hz}$ and lower frequencies were unlikely to have been mediated by the Pacinian channel. With both contactors, thresholds at almost all frequencies were significantly correlated with each but not with thresholds at $250 \mathrm{~Hz}$ (Table 4), suggesting that the same channel had the lowest threshold with both contactors at all frequencies less than $250 \mathrm{~Hz}$. The $250-\mathrm{Hz}$ thresholds on the volar forearm with the larger contactor were correlated with $250-\mathrm{Hz}$ thresholds with the same contactor on the fingertip, which are assumed to be mediated by the Pacinian channel (Table 5). So, while forearm thresholds at $250 \mathrm{~Hz}$ (particularly with the larger contactor) are likely to have been mediated by the Pacinian channel, thresholds at lower frequencies are likely to have been mediated by non-Pacinian channels.

Verrillo and Bolanowski (1986) reported that thresholds at frequencies up to $250 \mathrm{~Hz}$ on the volar forearm obtained with a 1-mm diameter contactor (the geometry of the small contactor in the current study) were probably mediated by non-Pacinian channels. They based this conclusion partly on thresholds at high frequencies being invariant with a change of temperature, whereas a dependence on temperature would be expected with the Pacinian channel. The current thresholds on the volar forearm at $125 \mathrm{~Hz}$ and lower frequencies may be determined by the non-Pacinian channel, namely hair follicle afferent (HFA) fibers defined by Zachariah et al. (2001) and Mahns et al. (2006).

The thresholds determined in the present study decreased with increasing area of excitation at only one frequency $(250 \mathrm{~Hz})$, whereas Bolanowski et al. (1994) reported significant reductions in thresholds at all frequencies between 45 and $500 \mathrm{~Hz}$. Whilst both the current study and Bolanowski et al. (1994) used a 1-mm diameter contactor, the larger (6 mm) contactor used in the present study was smaller than the 19.2-mm diameter contactor used by Bolanowski et al. (1994). The smaller extent of spatial summation in the current study may be due to the smaller area of excitation of the larger contactor compared to that used by Bolanowski et al. (1994).

Large toe

Thresholds at the large toe were lower with the larger area of excitation at most frequencies, but the involvement of the Pacinian channel is not clearly evident. There was reduced spatial 
summation (3.6 dB per doubling of excitation area) compared to $10.2 \mathrm{~dB}$ at the fingertip and no spatial summation at $250 \mathrm{~Hz}$ where the Pacinian channel would be expected to be dominant. This may have been a consequence of a relatively sparse and random distribution of FA II units on the sole of the foot, as observed by Kennedy and Inglis (2006), unlike the more uniform distribution of FA II units on the hand, as observed by Johansson and Vallbo (1979). Moreover, there may be a greater receptive field size for FA II units at the foot compared to those at the hand: the median receptive field size of the FA II units at the foot estimated by Kennedy and Inglis (2002) was $284 \mathrm{~mm}^{2}$ (range 42-895 $\mathrm{mm}^{2}$ ), almost three times greater than that at the hand (median $101.3 \mathrm{~mm}^{2}$ ) estimated by Johansson and Vallbo (1980). Consequently, the increase in contactor size from $1 \mathrm{~mm}$ to $6 \mathrm{~mm}$ may not have been sufficient at the large toe to stimulate an increased number of afferent fibres in the Pacinian channel so as to exhibit spatial summation. This means that thresholds at the large toe cannot confidently be attributed to the Pacinian channel from the results of the present study.

Heel

The presence of spatial summation at all frequencies (from 8 to $250 \mathrm{~Hz}$ ) at the heel implies involvement of the Pacinian channel in the detection of vibration at the heel. Significant correlations between thresholds at each frequency with the larger contactor are also consistent with the Pacinian channel mediating all thresholds with the larger contactor (Table $3)$.

With the smaller contactor, two channels may have determined thresholds, one at low frequencies (less than $63 \mathrm{~Hz}$ ) and another at high frequencies (greater than $63 \mathrm{~Hz}$ ). Thresholds were significantly correlated within these low frequencies and within these high frequencies. Thresholds on the fingertip and thresholds on the heel were correlated at frequencies from 8 to $63 \mathrm{~Hz}$, suggesting a relationship between the sensitivity of the NPI channel (Meissner corpuscles) on the fingertip and on the heel.

The NPII channel has been reported to have the lowest threshold at high frequencies when vibration is delivered through a small contactor (e.g. Bolanowski et al., 1988). The NPII channel may have mediated high frequency thresholds at the heel with the small contactor in the present experiment. This is consistent with the small and large contactor thresholds at the heel not being highly correlated at high frequencies, suggesting that different receptors determined thresholds with each contactor. 


\section{Conclusions}

Over the frequency range 8 to $250 \mathrm{~Hz}$, vibrotactile thresholds were lowest on the fingertip, consistent with a greater density of mechanoreceptors at this location compared to the volar forearm, the large toe, and the heel. The volar forearm was the least sensitive location. The sensitivity of the sole of the foot varied with location and with frequency of excitation: the large toe was more sensitive to low frequencies, whereas the heel was more sensitive to higher frequencies.

The thresholds are consistent with the Pacinian channel determining high frequency thresholds at the fingertip with both the smaller contactor $\left(7.1-\mathrm{mm}^{2}\right.$ excitation area) and the larger contactor (79- $\mathrm{mm}^{2}$ excitation area). Evidence of the Pacinian channel mediating thresholds on the volar forearm was limited to the highest frequency $(250 \mathrm{~Hz})$ with the larger contactor, suggesting non-Pacinian channels were responsible for most thresholds on the volar forearm with both the small and the large contactor. The roles of Pacinian and nonPacinian channels in mediating vibrotactile thresholds on the heel and the large toe are unclear; spatial summation at low and high frequencies suggests some influence of the Pacinian channel, while other evidence suggests an influence from non-Pacinian channels. 


\section{References}

Bartlett, G Stewart, J.D, Tamblyn, R and Abrahamowicz, M (1998) Normal distributions of thermal and vibration sensory thresholds, Muscle \& Nerve, 21, 367-374.

Békésy, G. v. (1947) A new audiometer. Acta Otolaryngol., 35, 411-422.

Burgess, P.R. Cutaneous Mechanoreceptors. In Handbook of Perception, Vol 3. E.C. Carterette and M.P. Friedman, eds. pp 219-249, Academic Press, New York (1973).

Bolanowski, S.J., Verrillo, R.T., 1982. Temperature and criterion effects in a somatosensory subsystem: A neurophysiological and psychophysical study. Journal of Neurophysiology. 48, 836-855.

Bolanowski,S.J., Gescheider,G.A., Verrillo,R.T., and Checkosky,C.M. (1988) Four channels mediate the mechanical aspects of touch. Journal of the Acoustical Society of America 84, 1680-1694.

Bolanowski, S.J., Gescheider, G.A., and Verrillo, R.T (1994) Hairy skin: Psychophysical channels and their physiological substrates. Somatosensory and Motor Research 11 (3) 279-290.

Capraro,A.J., Verrillo,R.T., Zwislocki,J.J. 1979. Psychophysical evidence for a triplex system of cutaneous mechano-reception. Sensory Processes 3: 334-352.

Edin, B.B., Abbs ,J.,H (1991) Finger movement responses of cutaneous mechanoreceptors in the dorsal skin of the human hand. Journal of Neurophysiology, 65,: 657-670.

Gescheider,G.A., Bolanowski,S.J., Pope,J.V., and Verrillo,R.T. (2002) A four-channel analysis of the tactile sensitivity of the fingertip: frequency selectivity, spatial summation, and temporal summation. Somatosensory and Motor Research 19, 114-124.

Greenspan,J.D. and Bolanowski,S.J. (1996) Psychophysics of tactile perception and its peripheral physiological basis. Pain and Touch. Academic Press.

Gregg, E.C Jr (1951). Absolute measurement of the vibratory threshold. AMA Arch Neurol Psychiatry 66 (4) 403-411.

Harada,N. and Griffin,M.J. (1991) Factors Influencing Vibration Sense Thresholds Used to Assess Occupational Exposures to Hand Transmitted Vibration. British Journal of Industrial Medicine 48, 185-192.

Järvilehto, TI., Hämäläinen, H.E., Soininen, K.A. (1981) Peripheral neural basis of tactile sensations in man. II. Characteristics of human mechanoreceptors in the hairy skin and correlations of their activity with tactile sensations. Brain Research. 219: 13-27.

Johansson,R.S., Landstrom,U., and Lundstrom,R. (1982) Sensitivity to Edges of Mechanoreceptive Afferent Units Innervating the Glabrous Skin of the Human Hand. Brain Research 244, 27-32.

Johansson,R.S. and Vallbo,A.B. (1979) Tactile sensibility in the human hand: relative and absolute densities of four types of mechanoreceptive units in glabrous skin. Journal of Physiology (Lond) 286, 283.

Kekoni, J, Hamalainen, H, Rautio, J and Tukeva, T (1989) Mechanical sensibility of the sole of the foot determined with vibratory stimuli of varying frequency, Experimental Brain Research, 78, 419-424. 
Kennedy, P.M. and Inglis, J.T (2002) Distribution and behaviour of glabrous cutaneous receptors in the human foot sole, Journal of Physiology-London, 538, 995-1002.

Kowalzik, R, Hermann, B, Biedermann, $\mathrm{H}$ and Peiper, U (1996) Two-point discrimination of vibratory perception on the sole of the human foot, Foot \& Ankle International, 17, 629-634.

Lindsell,C.J. (1997) Vibrotactile thresholds: effect of contact forces and skin indentation. Presented at the UK Group meeting on Human Response to Vibration, Southampton, 1719th September 1997.

Mahns, D.A., Perkins, N.M., Sahai, V. Robinson, L., and Rowe M.J. (2006) Vibrotactile frequency discrimination in human hairy skin. Journal of Neurophysiology 95, 1442-1450.

Nurse, M.A. and Nigg, B.M. (1999) Quantifying a relationship between tactile and vibration sensitivity of the human foot with plantar pressure distributions during gait, Clinical Biomechanics, 14, 667-672.

Sequiera, J.H., Ingram, J.T., and Brain, R.T. (1947) Diseases of the skin. J \& A Churchill Ltd, London.

Trulsson, M. (2001) Mechanoreceptive afferents in the human sural nerve. Experimental Brain Research 137: 111-116.

Vallbo, A.B, Olausson, H, Wessberg, J., and Kakuda, N. (1995) Receptive field characteristics of tactile units with myelinated afferents in hairy skin of human subjects. Journal of Physiology, 483(3) 783-795.

Verrillo,R.T. (1963) Effect of probe area on vibrotactile thresholds. Journal of the Acoustical Society of America 35, 1962-1966.

Verrillo, R.T. (1962) Investigation of some parameters of the cutaneous threshold for vibration. Journal of the Acoustical Society of America, 34, 1768-1773.

Verrillo RT (1966) Vibrotactile thresholds for hairy skin. Journal of Experimental Psychology 72(1) 47-50.

Verrillo, R.T., Bolanowski, S.J (1986) The effects of skin temperature on the psychophysical responses to vibration on glabrous and hairy skin. Journal of the Acoustical Society of America 80 (2) 528-532.

Verrillo, R.T., Bolanowski, S.J., Gescheider, G.A (2002) Effect of aging on the subjective magnitude of vibration. Somatosensory and Motor Research, 19 (3) 238-244.

Whitehouse, D.J., Morioka, M., and Griffin, M.J (2006) Effect of contact location on vibrotactile thresholds at the fingertip. Somatosensory and Motor Research. In press.

Wilska, A. (1954) On the vibrational sensitivity in different regions of the body surface. Acta Physiol Scand. 18; 31 (2-3) 284-289.

Zachariah, M.K., Coleman, G.T., Mahns, D.A., Zhang, H.Q, and Rowe, M.J. (2001) Transmission security for single, hair follicle-related tactile afferent fibers and their target chneate neurons in cat. Journal of Neurophysiology 86, 900-911. 


\section{FIGURE CAPTIONS}

Figure 1 Median vibrotactile thresholds at four locations with the 1-mm and 6-mm contactors.

Figure 2 Effect of changing the diameter of the contactor (and area of excitation) on median

vibrotactile thresholds at each location (Error bars represent inter-quartile ranges). 
Table 1 Contact conditions and threshold measurement parameters.

\begin{tabular}{|c|c|c|}
\hline \multicolumn{3}{|l|}{ Test Stimuli } \\
\hline Frequency $(\mathrm{Hz})$ & \multicolumn{2}{|c|}{$8,16,31.5,63,125,250$} \\
\hline Measurement duration (seconds) & \multicolumn{2}{|c|}{45} \\
\hline \multicolumn{3}{|l|}{ Skin-stimulator contact } \\
\hline Probe diameter & $1 \mathrm{~mm}$ & $6 \mathrm{~mm}$ \\
\hline Probe-surround gap & $1 \mathrm{~mm}$ & $2 \mathrm{~mm}$ \\
\hline Area of excitation & $7.1 \mathrm{~mm}^{2}$ & $79 \mathrm{~mm}^{2}$ \\
\hline Push force on surround & \multicolumn{2}{|c|}{$2 \mathrm{~N}$} \\
\hline Probe height relative to surround & \multicolumn{2}{|c|}{ Flush } \\
\hline Probe contact force & \multicolumn{2}{|c|}{ Not controlled } \\
\hline \multicolumn{3}{|l|}{ Algorithm } \\
\hline Psychophysical method & \multicolumn{2}{|c|}{ von Békésy } \\
\hline Initial step rate & \multicolumn{2}{|c|}{$5 \mathrm{~dB} / \mathrm{s}$} \\
\hline Testing step rate & \multicolumn{2}{|c|}{$3 \mathrm{~dB} / \mathrm{s}$} \\
\hline Reversals & \multicolumn{2}{|c|}{ At least 6 reversals (6 peaks and 6 troughs) } \\
\hline Subject response & \multicolumn{2}{|c|}{ Automatic, using a stop button } \\
\hline
\end{tabular}


Table 2 Median vibrotactile thresholds ( $\mathrm{ms}^{-2}$ r.m.s.) and inter-quartile range (IQR) for each frequency and contact location for the 1-mm and 6-mm contactors.

\begin{tabular}{|l|l|l|l|l|l|l|l|l|l|}
\hline \multicolumn{2}{|c|}{} & \multicolumn{2}{l|}{ Fingertip } & \multicolumn{2}{l|}{ Volar } & Forearm & \multicolumn{2}{l|}{ Large Toe } & \multicolumn{2}{l|}{ Heel } \\
\hline \multirow{2}{*}{ Frequency } & $1-\mathrm{mm}$ & $6-\mathrm{mm}$ & $1-\mathrm{mm}$ & $6-\mathrm{mm}$ & $1-\mathrm{mm}$ & $6-\mathrm{mm}$ & $1-\mathrm{mm}$ & $6-\mathrm{mm}$ \\
\hline \multirow{3}{*}{8} & Median & 0.03 & 0.04 & 0.52 & 0.56 & 0.17 & 0.12 & 0.31 & 0.18 \\
\cline { 2 - 11 } & IQR & 0.04 & 0.03 & 0.81 & 0.78 & 0.15 & 0.12 & 0.30 & 0.28 \\
\hline \multirow{3}{*}{36} & Median & 0.04 & 0.06 & 1.04 & 0.92 & 0.31 & 0.18 & 0.78 & 0.34 \\
\cline { 2 - 10 } & IQR & 0.05 & 0.04 & 2.36 & 1.27 & 0.44 & 0.25 & 0.61 & 0.35 \\
\hline \multirow{3}{*}{63.5} & Median & 0.13 & 0.17 & 2.50 & 1.86 & 0.52 & 0.48 & 1.36 & 0.58 \\
\cline { 2 - 10 } & IQR & 0.15 & 0.10 & 2.46 & 3.28 & 0.79 & 0.41 & 1.28 & 0.44 \\
\hline \multirow{3}{*}{125} & Median & 0.61 & 0.22 & 5.95 & 3.77 & 1.36 & 0.89 & 2.36 & 1.05 \\
\cline { 2 - 10 } & IQR & 0.39 & 0.26 & 5.44 & 5.21 & 1.97 & 0.88 & 2.54 & 1.33 \\
\cline { 2 - 9 } & Median & 0.82 & 0.24 & 8.03 & 5.13 & 3.83 & 2.12 & 2.58 & 1.07 \\
\hline \multirow{2}{*}{250} & IQR & 1.34 & 0.25 & 11.00 & 11.50 & 3.67 & 2.62 & 2.39 & 1.35 \\
\cline { 2 - 8 } & IQR & 1.72 & 0.47 & 18.48 & 13.05 & 9.61 & 8.87 & 7.05 & 4.09 \\
\hline
\end{tabular}


Table 3 Correlation coefficients between vibrotactile thresholds at each frequency measured with $1-\mathrm{mm}$ and $6-\mathrm{mm}$ contactors $\left({ }^{*} p<0.05 ;{ }^{* *} p<0.01\right)$.

\begin{tabular}{|c|c|c|c|c|c|c|c|c|}
\hline & & & 8 & 16 & 31.5 & 63 & 125 & 250 \\
\hline \multirow{27}{*}{ 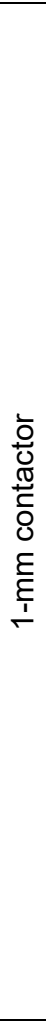 } & \multirow[t]{7}{*}{ Fingertip } & 8 & & $0.74^{* *}$ & $0.89^{* *}$ & 0.48 & 0.27 & 0.27 \\
\hline & & 16 & & & $0.82^{* *}$ & $0.65^{\star *}$ & 0.46 & 0.36 \\
\hline & & 31.5 & & & & 0.41 & 0.26 & 0.24 \\
\hline & & 63 & & & & & 0.44 & 0.37 \\
\hline & & 125 & & & & & & $0.82^{\star *}$ \\
\hline & & 250 & & & & & & \\
\hline & & & 8 & 16 & 31.5 & 63 & 125 & 250 \\
\hline & \multirow[t]{7}{*}{ Forearm } & 8 & & $0.83^{* *}$ & $0.65^{\star *}$ & $0.63^{\star *}$ & $0.61^{*}$ & $0.50^{*}$ \\
\hline & & 16 & & & $0.77^{* *}$ & $0.68^{* *}$ & $0.62^{*}$ & 0.41 \\
\hline & & 31.5 & & & & $0.59^{*}$ & 0.42 & 0.17 \\
\hline & & 63 & & & & & $0.55^{*}$ & 0.49 \\
\hline & & 125 & & & & & & $0.53^{*}$ \\
\hline & & 250 & & & & & & \\
\hline & & & 8 & 16 & 31.5 & 63 & 125 & 250 \\
\hline & \multirow[t]{7}{*}{ Large toe } & 8 & & $0.53^{*}$ & $0.84^{* *}$ & $0.84^{* *}$ & 0.31 & 0.24 \\
\hline & & 16 & & & $0.77^{* *}$ & $0.68^{* *}$ & $0.62^{*}$ & -0.09 \\
\hline & & 31.5 & & & & $0.93^{* *}$ & 0.42 & 0.25 \\
\hline & & 63 & & & & & $0.57^{*}$ & 0.35 \\
\hline & & 125 & & & & & & $0.54^{*}$ \\
\hline & & 250 & & & & & & \\
\hline & & & 8 & 16 & 31.5 & 63 & 125 & 250 \\
\hline & \multirow[t]{6}{*}{ Heel } & 8 & & $0.73^{* *}$ & $0.82^{* *}$ & $0.55^{*}$ & 0.40 & 0.27 \\
\hline & & 16 & & & $0.71^{* *}$ & $0.62^{*}$ & 0.46 & 0.49 \\
\hline & & 31.5 & & & & $0.56^{*}$ & 0.18 & 0.10 \\
\hline & & 63 & & & & & $0.66^{* *}$ & $0.79^{\star *}$ \\
\hline & & 125 & & & & & & $0.86^{* *}$ \\
\hline & & 250 & & & & & & \\
\hline \multirow{28}{*}{ 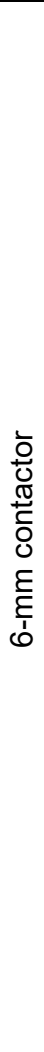 } & & & 8 & 16 & 31.5 & 63 & 125 & 250 \\
\hline & \multirow[t]{7}{*}{ Fingertip } & 8 & & $0.57^{*}$ & $0.74^{\star *}$ & $0.55^{*}$ & 0.24 & 0.37 \\
\hline & & 16 & & & $0.78^{* *}$ & 0.31 & 0.35 & 0.09 \\
\hline & & 31.5 & & & & $0.59^{*}$ & $0.57^{*}$ & 0.19 \\
\hline & & 63 & & & & & $0.69^{* *}$ & $0.54^{*}$ \\
\hline & & 125 & & & & & & $0.52^{*}$ \\
\hline & & 250 & & & & & & \\
\hline & & & 8 & 16 & 31.5 & 63 & 125 & 250 \\
\hline & \multirow[t]{7}{*}{ Forearm } & 8 & & $0.76^{* *}$ & $0.84^{* *}$ & $0.55^{*}$ & $0.65^{\star *}$ & 0.45 \\
\hline & & 16 & & & $0.77^{* *}$ & 0.41 & $0.58^{*}$ & 0.29 \\
\hline & & 31.5 & & & & 0.47 & $0.71^{* *}$ & 0.38 \\
\hline & & 63 & & & & & $0.69^{* *}$ & $0.82^{* *}$ \\
\hline & & 125 & & & & & & $0.58^{*}$ \\
\hline & & 250 & & & & & & \\
\hline & & & 8 & 16 & 31.5 & 63 & 125 & 250 \\
\hline & \multirow[t]{7}{*}{ Large toe } & 8 & & $0.83^{* *}$ & $0.84^{* *}$ & $0.52^{*}$ & 0.31 & 0.18 \\
\hline & & 16 & & & $0.70^{* *}$ & 0.31 & $0.58^{*}$ & -0.12 \\
\hline & & 31.5 & & & & $0.51^{*}$ & $0.59^{*}$ & 0.37 \\
\hline & & 63 & & & & & $0.56^{*}$ & $0.59^{*}$ \\
\hline & & 125 & & & & & & $0.63^{*}$ \\
\hline & & 250 & & & & & & \\
\hline & & & 8 & 16 & 31.5 & 63 & 125 & 250 \\
\hline & \multirow[t]{6}{*}{ Heel } & 8 & & $0.75^{\star *}$ & $0.78^{* *}$ & $0.51^{*}$ & $0.62^{\star *}$ & $0.50^{*}$ \\
\hline & & 16 & & & $0.63^{* *}$ & 0.48 & $0.52^{*}$ & 0.40 \\
\hline & & 31.5 & & & & $0.71^{* *}$ & $0.53^{*}$ & $0.72^{\star *}$ \\
\hline & & 63 & & & & & $0.60^{*}$ & $0.82^{\star *}$ \\
\hline & & 125 & & & & & & $0.72^{\star *}$ \\
\hline & & 250 & & & & & & \\
\hline
\end{tabular}


Table 4 Correlation coefficients between vibrotactile thresholds measured with the 1-mm and 6 -mm contactors $\left({ }^{*} p<0.05 ;{ }^{* *} p<0.01\right)$.

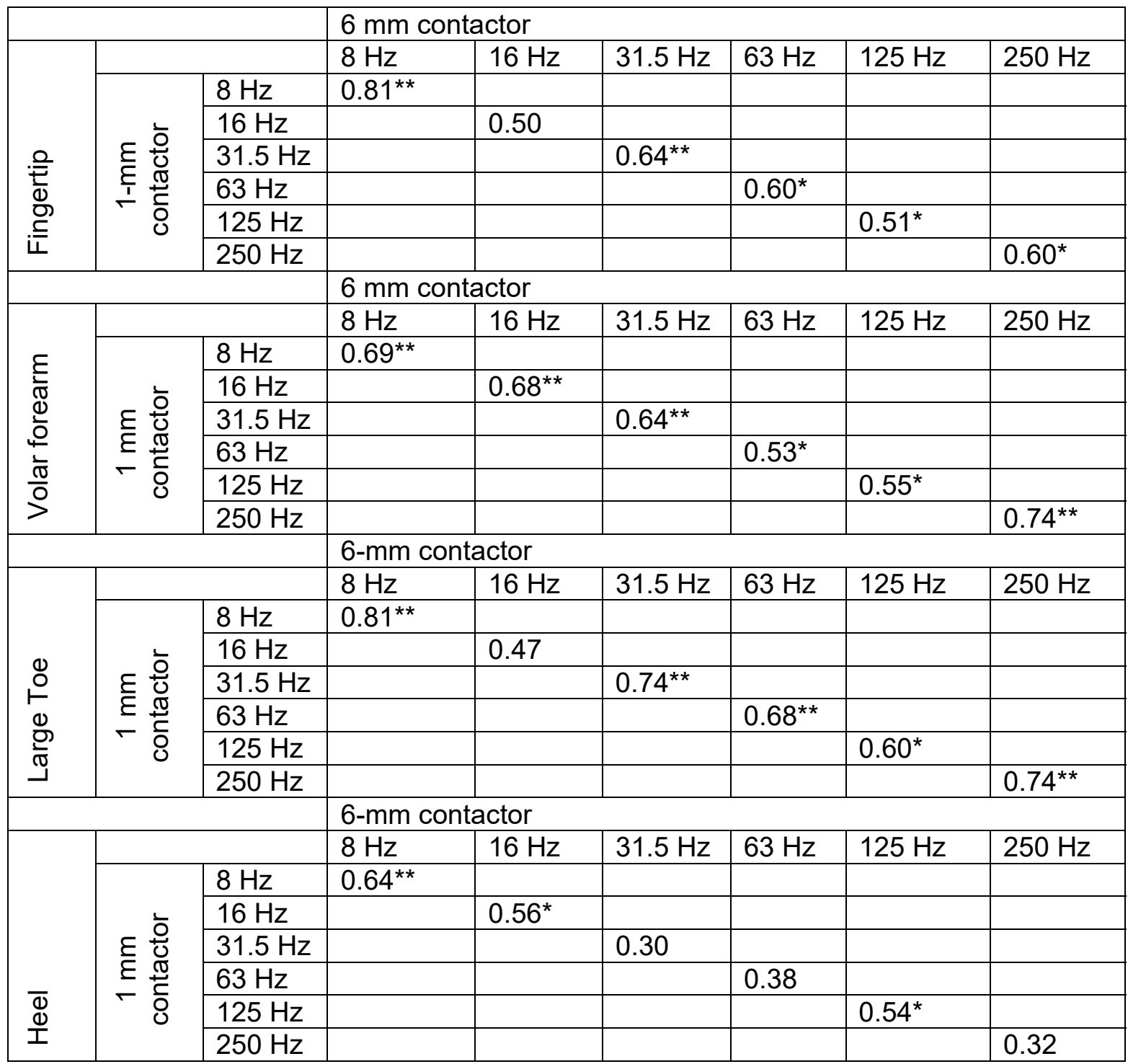


Table 5 Correlation coefficients between vibrotactile thresholds at each location measured with $1-\mathrm{mm}$ and $6 \mathrm{~mm}$ contactors $\left({ }^{*} p<0.05 ;{ }^{* *} p<0.01\right)$.

\begin{tabular}{|c|c|c|c|c|c|}
\hline & & & Forearm & Large Toe & Heel \\
\hline \multirow{24}{*}{ 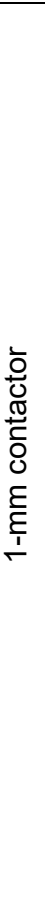 } & \multirow[t]{4}{*}{$8 \mathrm{~Hz}$} & Fingertip & $0.51^{*}$ & 0.37 & $0.79^{* *}$ \\
\hline & & Forearm & & $0.56^{*}$ & $0.61^{*}$ \\
\hline & & Large Toe & & & 0.49 \\
\hline & & Heel & & & \\
\hline & \multirow[t]{4}{*}{$16 \mathrm{~Hz}$} & Fingertip & $0.64^{* *}$ & $0.65^{\star *}$ & $0.71^{* *}$ \\
\hline & & Forearm & & $0.59^{*}$ & 0.24 \\
\hline & & Large Toe & & & 0.48 \\
\hline & & Heel & & & \\
\hline & \multirow[t]{4}{*}{$31.5 \mathrm{~Hz}$} & Fingertip & 0.37 & 0.36 & $0.63^{* *}$ \\
\hline & & Forearm & & 0.06 & 0.13 \\
\hline & & Large Toe & & & $0.53^{*}$ \\
\hline & & Heel & & & \\
\hline & \multirow[t]{4}{*}{$63 \mathrm{~Hz}$} & Fingertip & 0.44 & 0.21 & 0.31 \\
\hline & & Forearm & & 0.09 & 0.42 \\
\hline & & Large Toe & & & 0.37 \\
\hline & & Heel & & & \\
\hline & \multirow[t]{4}{*}{$125 \mathrm{~Hz}$} & Fingertip & 0.44 & 0.08 & 0.19 \\
\hline & & Forearm & & 0.22 & $0.82^{* *}$ \\
\hline & & Large Toe & & & 0.26 \\
\hline & & Heel & & & \\
\hline & \multirow[t]{4}{*}{$250 \mathrm{~Hz}$} & Fingertip & 0.49 & $0.69^{* *}$ & 0.37 \\
\hline & & Forearm & & 0.40 & 0.43 \\
\hline & & Large Toe & & & 0.42 \\
\hline & & Heel & & & \\
\hline & & & Forearm & Large Toe & Heel \\
\hline \multirow{24}{*}{ 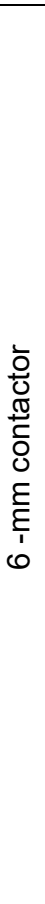 } & \multirow[t]{4}{*}{$8 \mathrm{~Hz}$} & Fingertip & 0.23 & 0.38 & 0.24 \\
\hline & & Forearm & & $0.64^{* *}$ & $0.53^{*}$ \\
\hline & & Large Toe & & & $0.70^{* *}$ \\
\hline & & Heel & & & \\
\hline & \multirow[t]{4}{*}{$16 \mathrm{~Hz}$} & Fingertip & 0.02 & $0.59^{*}$ & $0.67^{* *}$ \\
\hline & & Forearm & & 0.32 & 0.27 \\
\hline & & Large Toe & & & $0.64^{* *}$ \\
\hline & & Heel & & & \\
\hline & \multirow[t]{4}{*}{$31.5 \mathrm{~Hz}$} & Fingertip & -0.18 & 0.27 & 0.20 \\
\hline & & Forearm & & $0.58^{*}$ & 0.28 \\
\hline & & Large Toe & & & $0.60^{*}$ \\
\hline & & Heel & & & \\
\hline & \multirow[t]{4}{*}{$63 \mathrm{~Hz}$} & Fingertip & $0.51^{*}$ & 0.46 & 0.39 \\
\hline & & Forearm & & $0.57^{*}$ & 0.25 \\
\hline & & Large Toe & & & 0.07 \\
\hline & & Heel & & & \\
\hline & \multirow[t]{4}{*}{$125 \mathrm{~Hz}$} & Fingertip & 0.24 & 0.17 & -0.03 \\
\hline & & Forearm & & 0.49 & 0.10 \\
\hline & & Large Toe & & & $0.54^{*}$ \\
\hline & & Heel & & & \\
\hline & \multirow[t]{4}{*}{$250 \mathrm{~Hz}$} & Fingertip & $0.84^{* *}$ & 0.36 & 0.23 \\
\hline & & Forearm & & 0.33 & 0.27 \\
\hline & & Large Toe & & & -0.11 \\
\hline & & Heel & & & \\
\hline
\end{tabular}




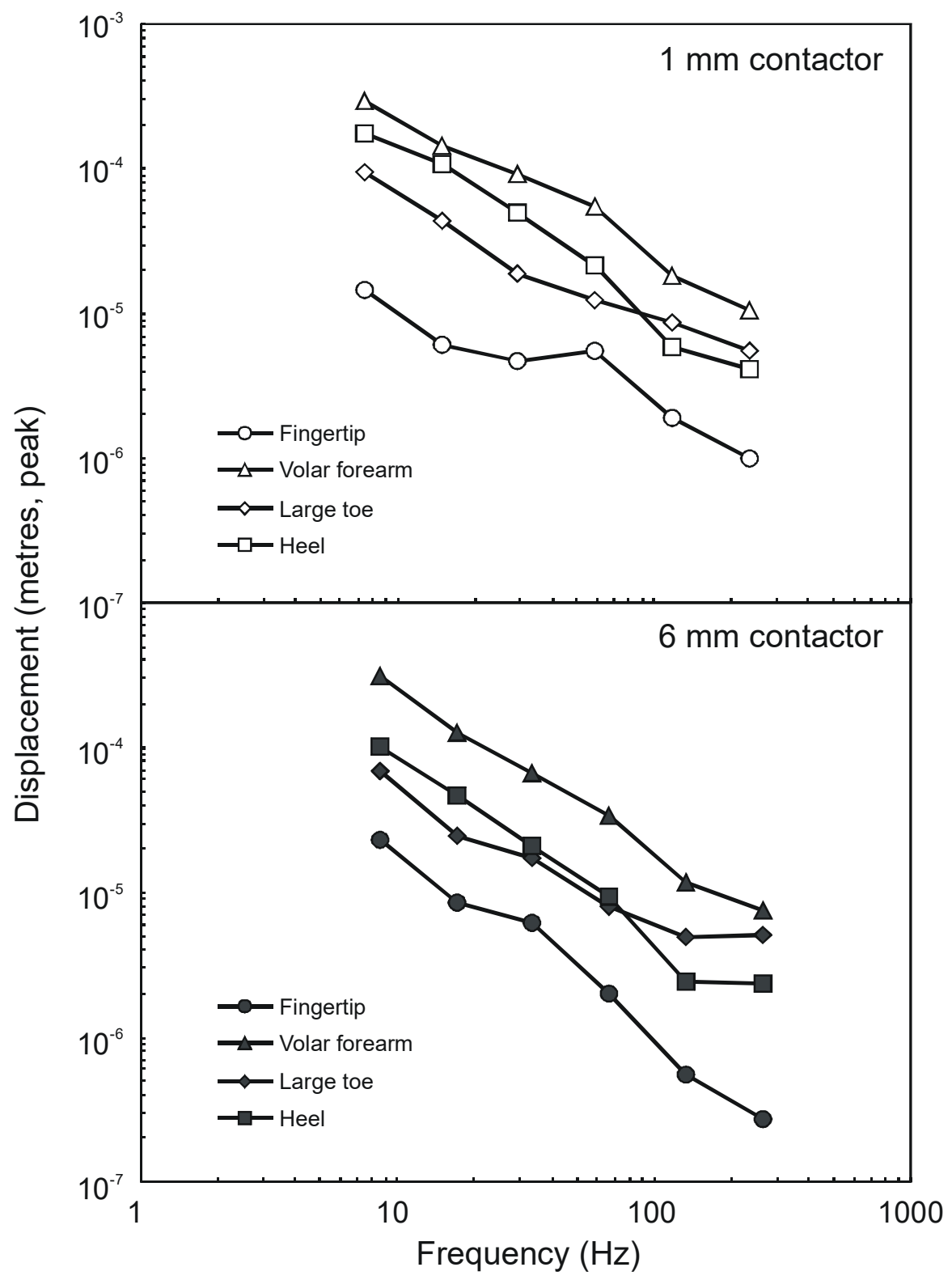

Figure 1 Median vibrotactile thresholds at four locations with the 1-mm and 6-mm contactors. 


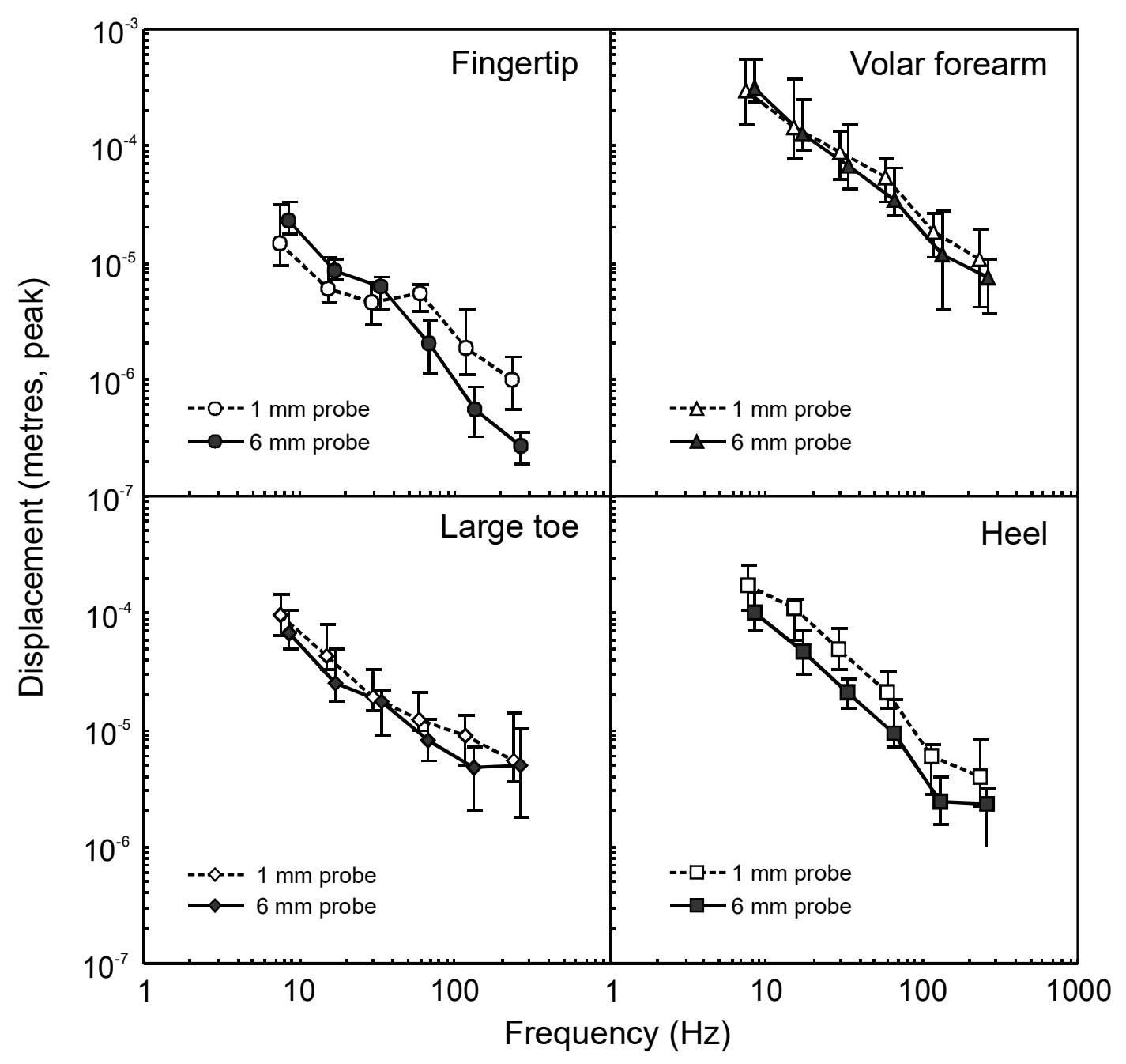

Figure 2 Effect of changing the diameter of the contactor (and area of excitation) on median vibrotactile thresholds at each location (Error bars represent inter-quartile ranges). 